\title{
Close-up of Valves
}
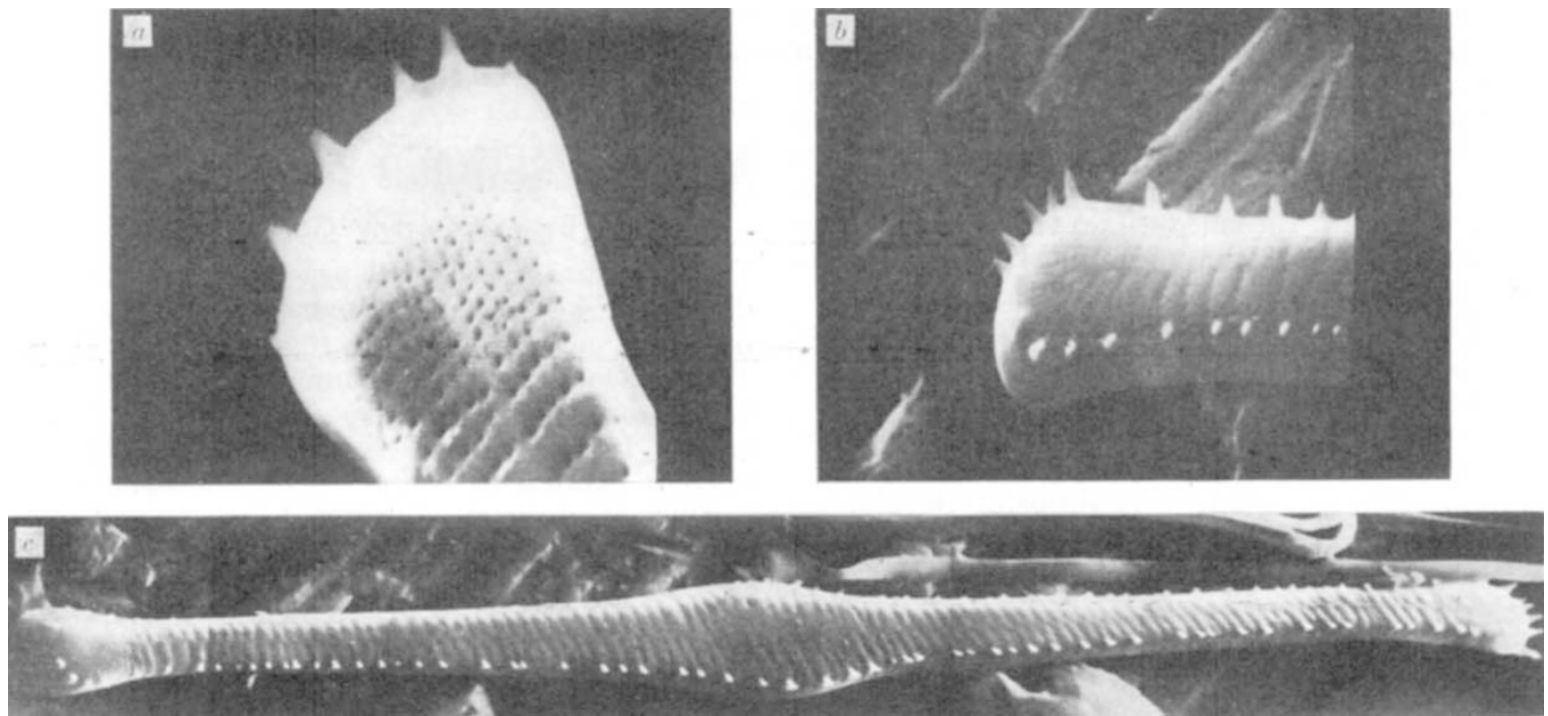

More fine structures on the valve face of the freshwater diatom Tabellaria flocculosa (Ehr.) Grun. var. asterionelloides (Grun.) Knuds. have been revealed by scanning electron microscopy. These micrographs were taken by Mrs S. Luff of the Central Electricity Research Laboratories on a Cambridge Stereoscan (Mark II) at $30 \mathrm{kV}$. All specimens were coated with gold.

The trans-apical striae described by Knudson (Annals of Botany, NS, 16, 421; 1952) are small pores approximately $0.1 \mu \mathrm{m}$ in diameter $(a, \times c .9,350)$. They are apparently simple with no connecting channels between them. Also, around the edge of the valve is a single line of spikes, approximately $0.5 \mu \mathrm{m}$ high, and at an obtuse angle to the valve face $(b, \times 5,600)$.

These pores or spikes have not been described before on the valve of T. flocculosa v. asterionelloides $(\times c .2,800)$ (they cannot be seen with the light microscope) and their physiological significance is still uncertain, although they normally provide a channel through the siliceous skeleton for the diffusion of substances into and out of the cell. The spatial arrangement of the spikes, together with the mucilage secreted by the cell, suggests that they are involved in colony formation, but this has yet to be confirmed. Other species of Tabellaria are being examined to see if these structures are characteristic of the whole genus.

\section{PLANT BREEDING}

\section{Cells hold Promise}

\section{by our Botany Correspondent}

A TREND for plant breeding to begin in the Petri dish rather than the flower pot is clear in the work of the John Innes Institute near Norwich, where several new techniques for producing hybrids and homozygotes are showing promise. The development of a new range of hybrid plants is the aim of a threepronged investigation of plant cell hybridization described in the institute's latest annual report (John Innes $1969,6 s)$.

In readiness for the day when it will be possible to fuse isolated plant protoplasts from different species, these naked contents of cells have been prepared from callus tissue of several species, including Nicotiana tabacum, tobacco, and Pisum sativum, the garden pea. Pectinase and cellulase have been used to break down the cell walls. For good yields of protoplasts, the calluses must be subcultured every few days to keep them in a state of active division. At present, methods of fixing and staining the protoplasts are being sought, so that fusion and division can be observed. In the light of past experience with plant tissue culture, the team engaged on, this work seem confident that, once cells have been induced to fuse, hybrid plants will probably not be difficult to rear.

Another possibility for achieving interspecific cell fusion stems from observations of nuclear fusion in endosperms-the food stores of seeds. On this evidence it was suggested that hybrid cells might be produced by mixing different endosperms together. So far progress has been confined to finding a potentially useful nutrient medium for the culture of endosperms. Asparagine has proved a useful constituentof these media.

The third new approach to hybridization involves in vitro fertilization, which would bypass incompatibility mechanisms which prevent interspecific crosses by blocking, for example, the growth of pollen tubes. Pollen and ovules of several species have been cultured, but attempts at cross-fertilization have not been very successful so far. One cross, however, was achieved between two varieties of tulip, but only roots, and not shoots subsequently developed from the ovular tissue.

As well as hybrids, plant breeders would often like to have new homozygous lines, and one way to obtain these from heterozygous plants is, of course, to treat haploid plants with some substance, such as colchicine, which doubles their chromosome number. But, apart from potatoes, haploids are hard to find, and so the staff at the John Innes Institute embarked on their programme of growing haploids from pollen grains.

They have found that the best time to culture anthers is at or just before the first pollon grain mitosis. It this mitosis has not occurred, the formation of an embryoid is assured, but after this the pollen grains seem to be committed to their normal role and cannot: be induced to develop into plantlets. Results indicate that one bud containing five anthers could yield a thousand homozygous plants. If these techniques could be applied to important food crops, not only would much breeding time be saved, but some homozygous lines would be available for the first time. 